\title{
Allergen-Induced Coexpression of bFGF and TGF- $\beta 1$ by Macrophages in a Mouse Model of Airway Remodeling: bFGF Induces Macrophage TGF- $\beta 1$ Expression in vitro
}

\author{
Hye Young Yum ${ }^{a, b}$ Jae Youn Cho ${ }^{a}$ Marina Miller ${ }^{a}$ David H. Broide ${ }^{a}$

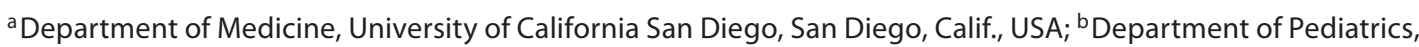 \\ Seoul Medical Center of Korea, Seoul, Korea
}

\section{Key Words}

Eosinophils • Allergy • Transforming growth factor- $\beta 1$ •

Basic fibroblast growth factor

\begin{abstract}
Background: Basic fibroblast growth factor (bFGF) is a cytokine that is mitogenic for fibroblasts and smooth muscle and may play a role in airway remodeling in asthma. We have used a mouse model of chronic ovalbumin (OVA) allergeninduced airway remodeling to determine whether bFGF and fibroblast growth factor receptor- 1 are expressed and regulated by corticosteroids in the airway, as well as to determine whether bFGF mediates expression of another proremodeling cytokine, transforming growth factor (TGF)- $\beta 1$. Methods: The airway levels and localization of bFGF, FGF receptor- 1 and TGF- $\beta 1$ were determined by ELISA, immunohistology and image analysis in the remodeled airways of chronic OVA-challenged mice treated with either corticosteroids or diluent. In vitro cultures of bone narrow-derived macrophages were used to determine whether bFGF induced TGF$\beta 1$ expression. Results: Mice chronically challenged with OVA developed significant airway remodeling that was associated with significantly increased levels of bFGF and TGF$\beta 1$. Immunohistochemistry demonstrated significantly increased bFGF and FGF receptor-1 expression by peribronchial F4/80+ cells. Double-label immunofluorescence
\end{abstract}

microscopy studies demonstrated that peribronchial macrophages coexpressed bFGF and TGF- $\beta 1$. In vitro studies demonstrated that incubation of bone marrow-derived macrophages with bFGF induced expression of TGF- $\beta 1$. Mice treated with corticosteroids and subjected to chronic OVA challenge had significantly reduced levels of bFGF, FGF receptor-1, peribronchial TGF- $\beta 1+$ cells and airway remodeling. Conclusions: Overall, this study demonstrates that allergen challenge stimulates peribronchial macrophages to coexpress bFGF and TGF- $\beta 1$ and that bFGF may potentiate macrophage release of TGF- $\beta 1$ through autocrine and/or paracrine pathways.

Copyright $\odot 2010$ S. Karger AG, Basel

\section{Introduction}

Asthma is a disease that is characterized by airway inflammation, airway hyperreactivity and airway remodeling [1]. Basic fibroblast growth factor (bFGF), also known as fibroblast growth factor-2 (FGF-2), is a cytokine that has the potential to play an important role in airway remodeling in asthma based on its known functional effects on proliferation of smooth muscle $[2,3]$ and fibroblasts [4], as well as its proangiogenic properties [5]. In addition, human studies have demonstrated increased bFGF immunohistochemical staining in airway epithe-

\section{KARGER}

(c) 2010 S. Karger AG, Basel

Fax +4161306 1234 E-Mail karger@karger.ch www.karger.com www.karger.com/iaa
Correspondence to: Dr. David H. Broide

Department of Medicine, University of California San Diego

Biomedical Sciences Building, Room 5090

9500 Gilman Drive, La Jolla CA 92093-0635 (USA)

Tel. +1 858534 2374, Fax +1 858534 2110, E-Mail dbroide@ ucsd.edu 
lium in asthmatics compared to nonasthmatic controls [6], increased bFGF in sputum of mild asthmatics (forced expiratory volume in $1 \mathrm{~s} 89 \%$ predicted) compared to controls [7] and increased bFGF release into bronchoalveolar lavage (BAL) fluid 10 min after segmental allergen challenge [8].

bFGF is a member of the FGF gene family, which comprises 23 members [9-13] that share approximately 30$70 \%$ identity in their primary sequence [11]. Cellular sources of bFGF include macrophages [14], endothelial cells [14], mast cells [15], epithelial cells [14] and fibroblasts [14]. Like FGF-1 (also known as acidic FGF), bFGF does not contain a signal sequence for secretion $[10,11$, 13]. Although bFGF does not express a secretory signal peptide, it has been detected extracellulary in vitro [16, $17]$ and in vivo in subjects with asthma $[6,8]$. FGFs signal by binding to 1 of 4 high-affinity FGF receptors that have been identified (i.e. FGF receptor-1 to -4) $[10,11,13]$. Most FGFs bind to all 4 FGF receptors $[10,11,13]$. FGF receptors appear to be similar to other growth factor receptors in that dimerization of receptor monomers upon ligand binding activates the tyrosine kinase domain of the FGF receptor [12]. FGF receptor activation leads to tyrosine autophosphorylation of the receptor $[10,11,13]$. The glycosaminoglycans heparan sulfate and heparin have been shown to be critical for FGF receptor function $[10,11,13]$.

Although human studies have investigated the expression of bFGF in asthma [6-8], previous studies have not investigated whether bFGF and FGF receptors are expressed in allergen-induced airway remodeling. Therefore, in this study we have utilized a mouse model of allergen-induced airway remodeling to determine which cell types express bFGF and FGF receptor-1 in the remodeled airway, as well as to determine whether the expression of bFGF in the remodeled airway may upregulate expression of additional cytokines such as transforming growth factor (TGF)- $\beta 1$, which may play an important role in airway remodeling in asthma [18, 19]. Finally, we investigate whether corticosteroids influence levels of bFGF and FGF receptor-1 in the remodeled airway.

\section{Materials and Methods}

Mouse Model of Chronic Ovalbumin-Induced Airway Remodeling

Eight- to 10 -week-old BALB/c mice (16 mice/group; The Jackson Laboratory, Bar Harbor, Me., USA) were immunized subcutaneously on days $0,7,14$ and 21 with $25 \mu \mathrm{g}$ of ovalbumin (OVA;
OVA grade V, Sigma) adsorbed to $1 \mathrm{mg}$ of alum (Aldrich) in 200 $\mu \mathrm{l}$ of normal saline as previously described $[18,20]$. Intranasal OVA challenges $(20 \mu \mathrm{g} / 50 \mu \mathrm{l}$ in PBS $)$ were administered on days 27, 29 and 31 under isoflurane (Vedco Inc., St. Joseph, Mo., USA) anesthesia. Intranasal OVA challenges were then repeated twice a week for 3 months. Age- and sex-matched control mice were sensitized but not challenged with OVA during the 3-month study period. Mice were sacrificed $24 \mathrm{~h}$ after the final OVA challenge, and BAL fluid and the lungs were analyzed. Lungs from the different groups of mice were equivalently inflated with an intratracheal injection of a similar volume of $4 \%$ paraformaldehyde solution (Sigma Chemicals, St. Louis, Mo., USA) to preserve the pulmonary architecture and were processed as a batch for either histologic staining or immunostaining under identical conditions. Three to 5 fields were quantified on all stained and immunostained slides of lung tissue under identical light microscope conditions, including magnification $(\times 20)$, gain, camera position and background illumination, as previously described [18]. The quantitative histologic and image analysis of all coded slides was performed by research associates blinded to the coding of the slides. All animal experimental protocols were approved by the Animal Subjects Committee of the University of California San Diego.

Quantitation of bFGF Levels in BAL

The concentration of bFGF in BAL fluid was assayed by ELISA (R\&D Systems, Minneapolis, Minn., USA). The bFGF ELISA has a sensitivity of $3 \mathrm{pg} / \mathrm{ml}$.

\section{Quantitation of bFGF in the Lung}

Lung sections were processed for immunohistochemistry using an anti-bFGF antibody (Ab; Santa Cruz Biotechnology, Santa Cruz, Calif., USA) as previously described [18, 20]. Species- and isotype-matched Abs were used as controls. The number of bFGF+ cells was quantitated both in the lung (excluding the bronchial epithelium) and separately in the bronchial epithelium. The number of bFGF+ cells was quantitated in a $\times 20$ lung field by counting all the bFGF+ cells in the lung field (area of approximately $0.04 \mathrm{~mm}^{2}$ ). Results are expressed as the number of bFGF+ cells per square millimeter of lung field. In addition, the area of bronchial epithelial cells/bronchus staining positive for bFGF was quantitated.

Quantitation of FGF Receptor-1 Expression in the Lung

Lung sections were processed for immunohistochemistry using an anti-FGF receptor-1 Ab (Calbiochem, San Diego, Calif., USA) as previously described $[18,20]$. Species- and isotypematched Abs were used as controls. The number of FGF receptor- $1+$ cells was quantitated both in the peribronchial region (excluding the bronchial epithelium) and separately in the bronchial epithelium. Results are expressed as the number of peribronchial cells staining positive for FGF receptor-1 per bronchiole with an internal diameter of 150-200 $\mu \mathrm{m}$, as well as the area of bronchial epithelial cells/bronchus staining positive for FGF receptor-1.

Double-Label Immunofluorescence Staining with Anti-F4/80

$A b$ and either Anti-bFGF or Anti-FGF Receptor-1 Ab

Lung sections were also immunostained with both an F4/80 primary $\mathrm{Ab}$ (rat anti-mouse F4/80 antigen; Accurate Chemical \& Scientific Corporation, Westbury, N.Y., USA) and either a bFGF or FGF receptor-1 Ab to determine whether F4/80+ peribronchi- 
al cells expressed either bFGF or FGF receptor-1. The two different primary antibodies were detected using two different horseradish peroxidase (HRP) enzyme-labeled secondary antibodies with tyramide signal amplification (Molecular Probes) according to the manufacturer's instructions as previously described [18]. The anti-bFGF or anti-FGF receptor-1 Ab was detected with an HRP-labeled secondary Ab (Alexa 546, red), while the anti-F4/80 $\mathrm{Ab}$ was detected with a different HRP-labeled secondary Ab (Alexa 488, green). Cells coexpressing F4/80 and either bFGF or bFGF receptor-1 stain a blended yellow color.

TGF- $\beta 1$ Expression in Lung in vivo

The concentrations of TGF- $\beta 1$ in lung were assayed by ELISA as previously described [18]. Prior to the TGF- $\beta 1$ assay, the BAL fluid samples were treated with $2.5 \mathrm{~N}$ acetic acid to activate any latent TGF- $\beta 1$, as previously described $[18,20]$.

\section{Double-Label Immunofluorescence Staining to Detect}

\section{Coexpression of $b F G F$ and TGF- $\beta 1$}

Lung sections were also immunostained with both anti-bFGF and anti-TGF- $\beta 1$ Abs [20] to determine whether peribronchial cells co-expressed bFGF and TGF- $\beta 1$. The anti-bFGF Ab was detected with an HRP-labeled secondary Ab (Alexa 546, red), while the anti-TGF- $\beta 1 \mathrm{Ab}$ was detected with a different HRP-labeled secondary Ab (Alexa 488, green). Cells coexpressing bFGF and TGF- $\beta 1$ stain a blended yellow color.

\section{Immunohistochemistry to Detect Expression of bFGF and} TGF- $\beta 1$ by Peripheral Blood Mononuclear Cells

Peripheral blood was collected into EDTA-containing tubes from mice by means of cardiac puncture. Erythrocytes were lysed using a 1:10 solution of $100 \mathrm{~mm}$ potassium carbonate and $1.5 \mathrm{M}$ ammonium chloride. The remaining cells were resuspended in $1 \mathrm{ml}$ of PBS. To perform immunohistochemistry, $200 \mu \mathrm{l}$ of resuspended peripheral blood leukocytes were cytospun onto microscope slides and air-dried. Slides were immunostained with either an anti-bFGF Ab or an anti-TGF- $\beta 1 \mathrm{Ab}$ as described above. The percentage of mononuclear cells that stained positive for either bFGF or TGF- $\beta 1$ was recorded for each slide.

\section{Effects of bFGF on TGF- $\beta 1$ Expression by Bone}

Marrow-Derived Macrophages in vitro

In these experiments, $5 \times 10^{5}$ macrophages derived from culture of mouse bone marrow using methods previously described [21] were incubated with media alone or stimulated with bFGF (10 and $100 \mathrm{ng} / \mathrm{ml}$ ) in triplicate for $72 \mathrm{~h}$. Supernatants were collected and assayed for TGF- $\beta 1$ by ELISA (R\&D Systems) as previously described [20].

\section{Therapeutic Intervention with Corticosteroids}

To determine whether corticosteroids could modulate levels of bFGF and FGF receptor-1 expression, different groups of mice (16 mice/group) were administered either dexamethasone $(1 \mathrm{mg} / \mathrm{kg}$ in $100 \mu \mathrm{l}$ of sterile, endotoxin-free PBS) or diluent control intraperitoneally as previously described [22]. The first dose of corticosteroid or diluent was administered $6 \mathrm{~h}$ before the first intranasal OVA challenge, and the therapeutic intervention was continued daily for the duration of the 3-month period of twice weekly OVA challenges. We have previously demonstrated that this dose of corticosteroid inhibits airway remodeling in this mouse model
[22]. We also examined whether corticosteroids could reduce the number of bFGF+ cells per bronchus when administration of dexamethasone was only started at the end of the 3-month OVA sensitization and challenge protocol. In these 4-month experiments (3 months of OVA + no dexamethone, 1 month of OVA + dexamethasone), we used lung specimens stored at $-80^{\circ} \mathrm{C}$ from mice (16 mice/group) administered either dexamethasone ( $1 \mathrm{mg} /$ $\mathrm{kg}$ in $100 \mu \mathrm{l}$ of sterile, endotoxin-free PBS) or diluent daily for 1 month in experiments previously reported for outcomes other than bFGF [22].

\section{Airway Eosinophilic Airway Inflammation and Airway}

Remodeling

BAL eosinophils: BAL total eosinophil counts were assessed as previously described $[18,20]$.

Peribronchial fibrosis: The area of peribronchial trichrome staining in paraffin-embedded lung was outlined and quantified using a light microscope (Leica DMLS; Leica Microsystems Inc., New York, N.Y., USA) attached to an image analysis system (Image-Pro Plus; Media Cybernetics, Bethesda, Md., USA) as previously described $[18,20]$. Results are expressed as the area of trichrome staining per micrometer of basement membrane of bronchioles with an internal diameter of 150-200 $\mu \mathrm{m}$.

\section{Statistical Analysis}

Results in the different groups of mice were compared by ANOVA using the nonparametric Kruskal-Wallis test followed by posttesting using Dunn's multiple comparison of means. All results are presented as means \pm SEM. A statistical software package (Graph Pad Prism, San Diego, Calif., USA) was used for the analysis. $\mathrm{p}$ values of $<0.05$ were considered statistically significant.

\section{Results}

\section{Chronic OVA Challenge Induces Eosinophilic Airway} Inflammation and Airway Remodeling

Repetitive OVA challenge in wildtype mice induced a significant increase in the number of BAL eosinophils ( $\mathrm{p}=0.0001$, no OVA vs. OVA; fig. 1a) as well as features of airway remodeling, including peribronchial fibrosis as assessed by trichrome staining (fig. 2) as previously described $[18,20]$.

Administration of corticosteroids significantly reduced levels of BAL eosinophils in chronic OVA-challenged mice by approximately $85 \%(\mathrm{p}=0.0001$, no OVA vs. OVA; fig. 1a). Similarly, administration of corticosteroids significantly reduced levels of peribronchial fibrosis in chronic OVA-challenged mice as previously described (fig. 2a-d) [21, 22].

\section{Chronic OVA Challenge Induces Increased bFGF Levels in BAL Fluid \\ Chronic OVA challenge induced a significant increase in levels of BAL bFGF (OVA vs. no OVA: $158.7 \pm 12.2$ vs.}


Fig. 1. BAL eosinophils and bFGF levels. a The number of eosinophils in BAL fluid was quantitated by Wright-Giemsa staining in different groups of mice. $\mathbf{b}$ Levels of bFGF were quantitated by ELISA in BAL fluid derived from different groups of mice ( $\mathrm{n}=16 \mathrm{mice} /$ group). $\mathrm{CS}=$ Corticosteroids .
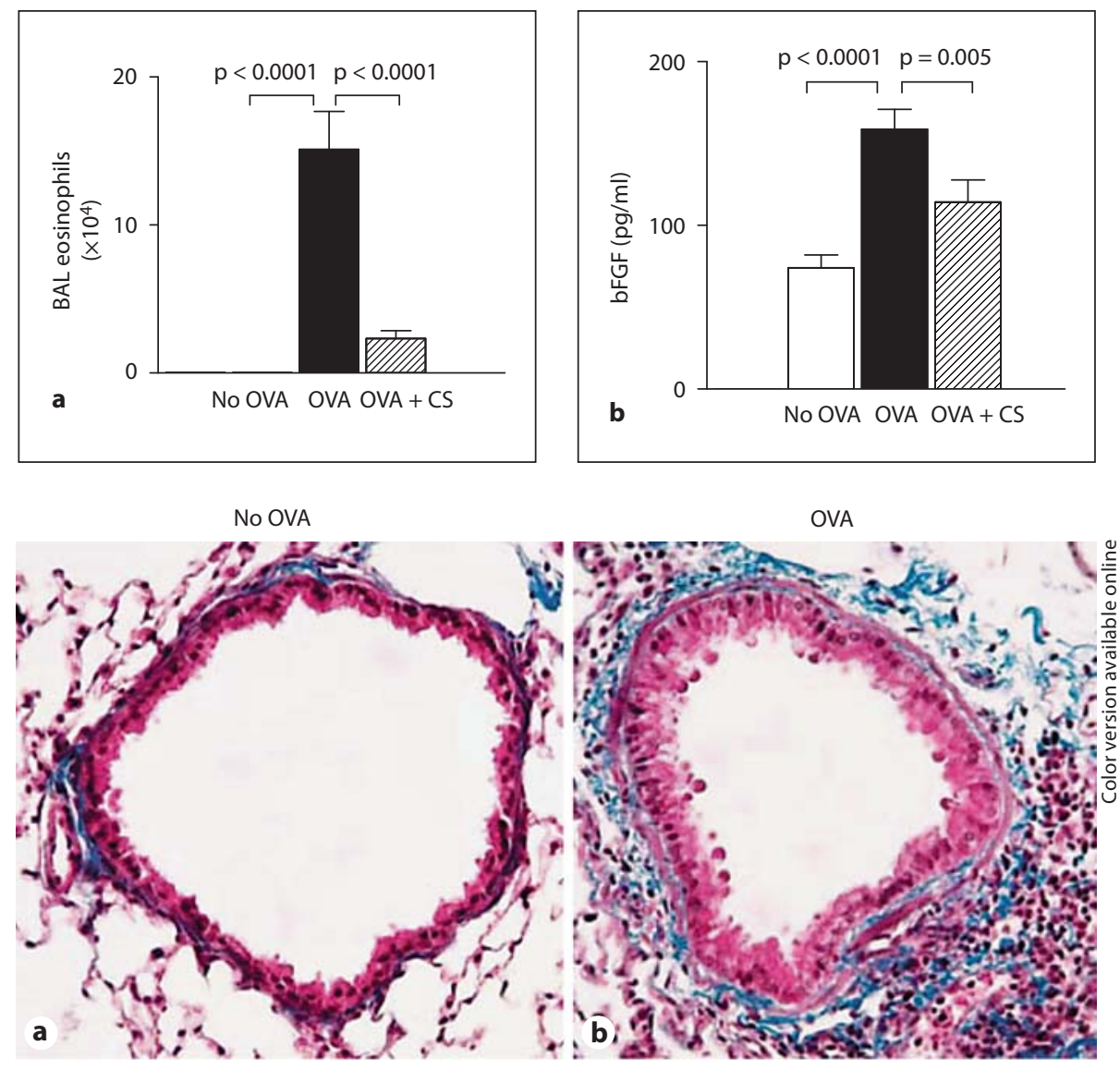

Fig. 2. Effect of corticosteroids on levels of peribronchial fibrosis. Lung sections from mice that received no OVA (a), chronic OVA (b) or chronic OVA + corticosteroids (CS) (c) were processed for staining with trichrome to detect peribronchial collagen deposition. $\mathbf{d}$ The area of peribronchial trichrome staining was quantitated by image analysis. Chronic OVA challenge induced a significant increase in the area of peribronchial trichrome staining $(\mathrm{p}<0.0001)$, which was significantly reduced by corticosteroid therapy $(\mathrm{p}<0.0001)(\mathrm{n}=16$ mice/group).
OVA + CS

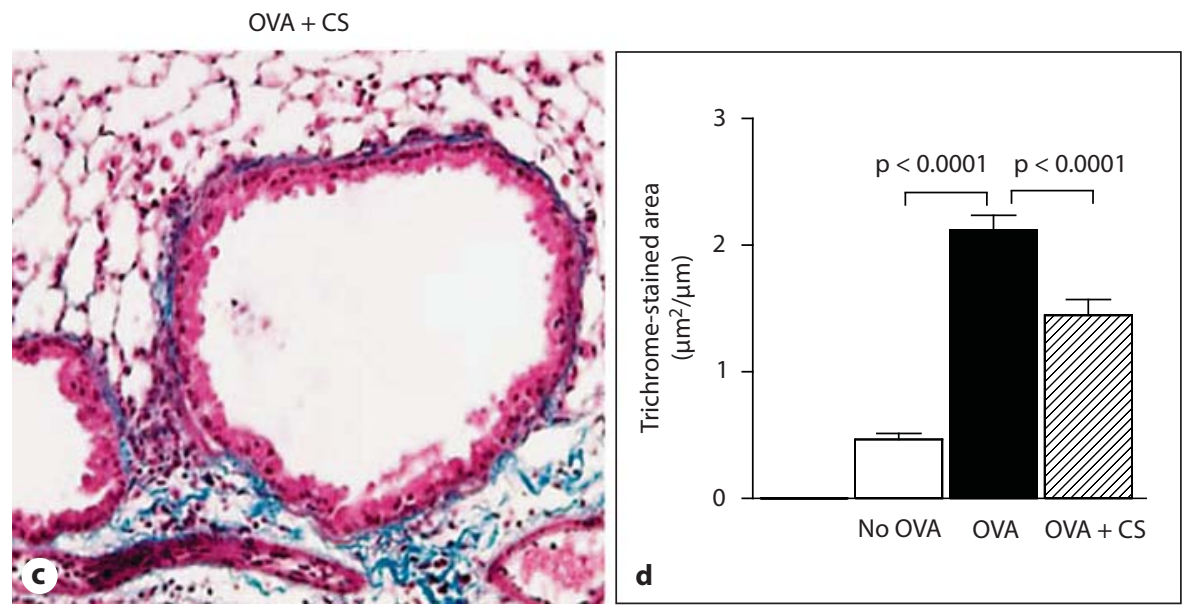

$74.3 \pm 7.8 \mathrm{pg} / \mathrm{ml} ; \mathrm{p}=0.0001$; fig. $1 \mathrm{~b})$. Corticosteroids significantly reduced levels of BAL bFGF in mice subjected to repetitive OVA challenge (corticosteroids + OVA vs. OVA: $114.2 \pm 13.5$ vs. $158.7 \pm 12.2 \mathrm{pg} / \mathrm{ml} ; \mathrm{p}=0.005$; fig. 1b).

bFGF and FGF Receptor-1
Chronic OVA Challenge Induces Expression of bFGF by Both F4/80+ Peribronchial Mononuclear Cells and Airway Epithelial Cells

To determine which cells express bFGF in response to allergen challenge, we immunostained lung sections with an anti-bFGF Ab. These studies demonstrated no 

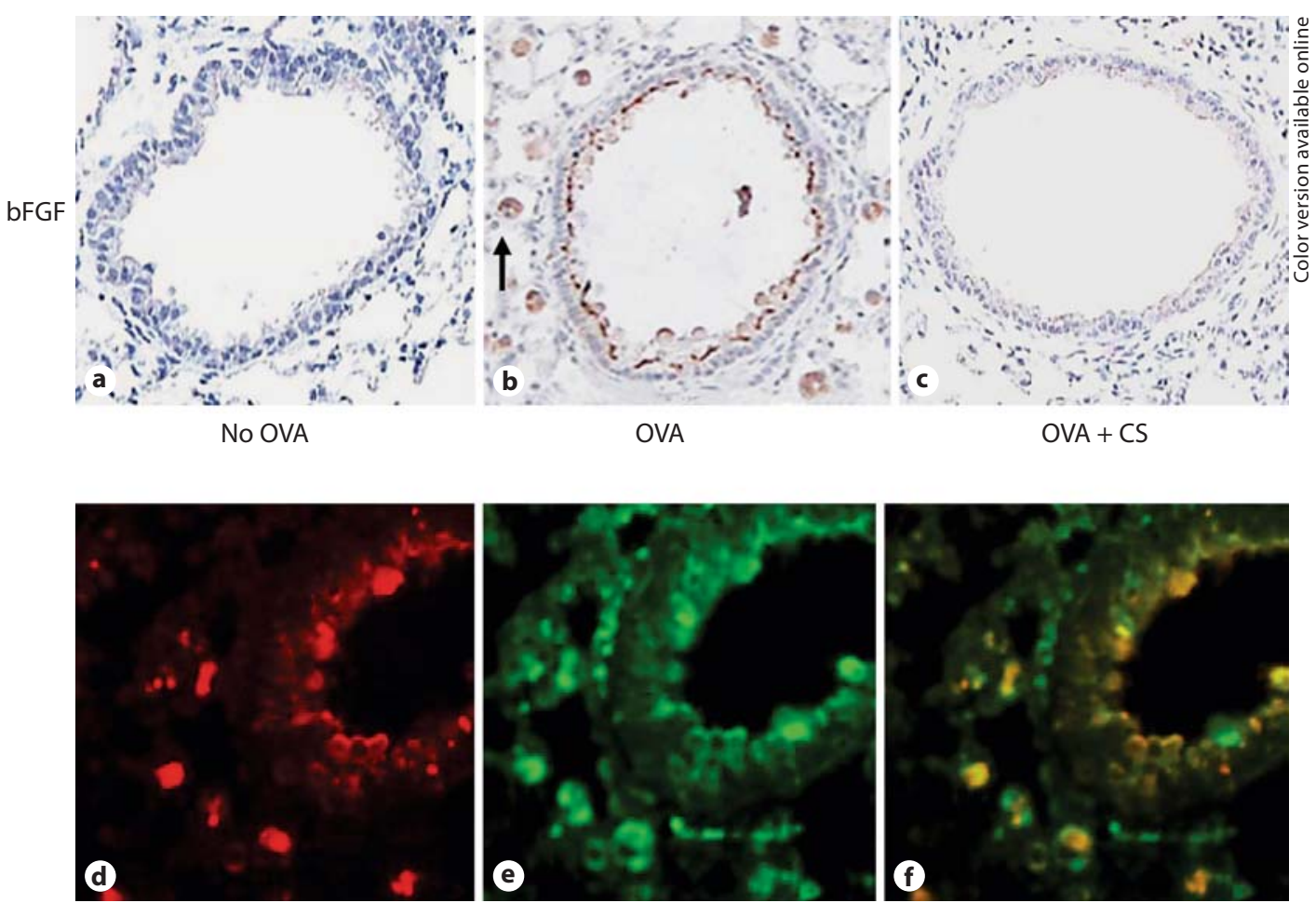

bFGF

$\mathrm{F} 4 / 80$

bFGF and F4/80

Fig. 3. bFGF is expressed by peribronchial mononuclear cells and airway epithelium. Lung sections from mice that received no OVA (a), chronic OVA (b) or chronic OVA + corticosteroids (CS) (c) were processed for immunostaining with an anti-bFGF Ab. The arrow in $\mathbf{b}$ indicates a mononuclear cell positive for bFGF.
Mice chronically challenged with OVA had peribronchial cells expressing bFGF (red immunofluorescence; d) as well as F4/80 (green immunofluorescence; e). Peribronchial cells expressing both bFGF and F4/80 demonstrated yellow immunofluorescence (f).
bFGF staining of non-OVA challenged lungs (fig. 3a), but significant bFGF immunostaining of both peribronchial mononuclear cells and airway epithelial cells in OVA-challenged mice (fig. 3b). Administration of corticosteroids to OVA-challenged mice significantly reduced levels of bFGF immunostaining of both peribronchial mononuclear cells and airway epithelial cells (fig. 3c).

To determine the identity of the peribronchial mononuclear cells that were bFGF+, we immunostained lung sections with both anti-bFGF (fig. 3d) and anti-F4/80 (fig. 3e) Abs. These studies demonstrated that the vast majority of bFGF+ cells were F4/80+ (fig. 3f).

\section{Quantitation of bFGF+ Peribronchial Mononuclear}

Cells and bFGF+ Airway Epithelial Cells

Utilizing image analysis, we quantitated the number of bFGF+ cells in the different groups of mice. Repetitive OVA challenge induced a significant increase in the num- ber of peribronchial bFGF+ cells (OVA vs. no OVA: 1,494 \pm 48 vs. $50 \pm 7 \mathrm{bFGF}+$ cells $/ \mathrm{mm}^{2} ; \mathrm{p}=0.0001$; fig. $4 \mathrm{a}$ ). Corticosteroids significantly reduced the number of peribronchial bFGF+ cells in mice subjected to repetitive OVA challenge (corticosteroids + OVA vs. OVA: $359 \pm$ 26 vs. $1,494 \pm 48 \mathrm{bFGF}+$ cells $/ \mathrm{mm}^{2} ; \mathrm{p}=0.0001$; fig. $4 \mathrm{a}$ ).

Repetitive OVA challenge in untreated mice also induced a significant increase in the area of airway epithelial bFGF immunostaining compared to non-OVA challenged mice (OVA vs. no OVA: $0.61 \pm 0.02$ vs. $0.11 \pm 0.01$ $\mu \mathrm{m}^{2} ; \mathrm{p}=0.0001$; fig. $\left.4 \mathrm{~b}\right)$. Corticosteroids significantly reduced the area of airway epithelial bFGF immunostaining in mice subjected to repetitive OVA challenge (corticosteroids + OVA vs. OVA: $0.40 \pm 0.02$ vs. $0.61 \pm 0.02$ $\mu \mathrm{m}^{2} ; \mathrm{p}=0.0001$; fig. $4 \mathrm{~b}$ ).

Corticosteroids also significantly reduced the number of bFGF+ cells/bronchus when corticosteroids were only administered for 1 month starting after 3 months of chronic OVA challenges (fig. 5). 
Fig. 4. Quantitation of bFGF+ peribronchial cells and bFGF+ epithelial area. Lungs from different groups of mice $(\mathrm{n}=$ 16 mice/group) were processed for immunohistochemistry with an anti-bFGF Ab. a The number of bFGF+ cells in the peribronchial region was quantitated by image analysis. $\mathbf{b}$ The area of airway epithelium that stained positive for bFGF was quantitated by image analysis. CS = Corticosteroids.
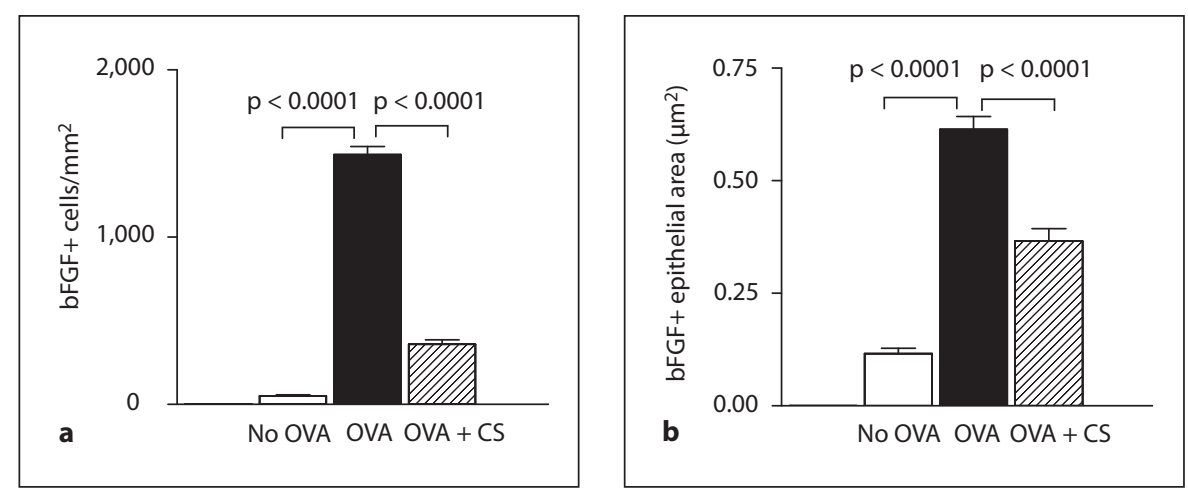

Chronic OVA Challenge Induces Expression of FGF

Receptor-1 Expression by F4/80+ Peribronchial Cells

To determine whether FGF receptor-1 (in addition to bFGF) was expressed in response to allergen challenge, we immunostained lung sections with an anti-FGF receptor-1 Ab. These studies demonstrated minimal FGF receptor-1 immunostaining of non-OVA challenged lungs (fig. 6a) but significant FGF receptor-1 immunostaining of peribronchial mononuclear cells without significant staining of airway epithelium in OVA-challenged mice (fig. 6b). This distribution of FGF receptor-1 expression (peribronchial mononuclear cells but not airway epithelium) differed from that of bFGF, which was expressed by both peribronchial inflammatory cells and airway epithelium. Administration of corticosteroids to OVA-challenged mice significantly reduced levels of FGF receptor-1 immunostaining of peribronchial mononuclear cells (fig. 6c).

\section{Chronic OVA Challenge Induces Expression of FGF \\ Receptor-1 by F4/80+ Peribronchial Mononuclear \\ Cells}

To determine the identity of the peribronchial mononuclear cells that were FGF receptor-1+, we immunostained lung sections with both anti-FGF receptor-1 (fig. 6d) and anti-F4/80 (fig. 6e) Abs. These studies demonstrated that the vast majority of FGF receptor-1+ cells were $\mathrm{F} 4 / 80+$ (fig. 6f).

\section{Quantitation of FGF Receptor-1+ Peribronchial Mononuclear Cells}

Utilizing image analysis, we quantitated the number of FGF receptor-1+ cells in the different groups of mice. Repetitive OVA challenge induced a significant increase in the number of peribronchial FGF receptor-1+ cells (OVA vs. no OVA: $30.1 \pm 5.2$ vs. $0.3 \pm 0.2$ FGF receptor- $1+$

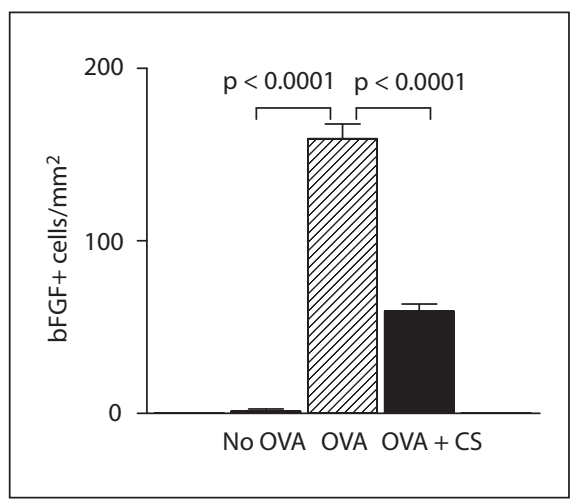

Fig. 5. Effect of corticosteroids (CS) administered after 3 months of chronic OVA challenge on numbers of bFGF+ cells/bronchus. Corticosteroids or diluent were administered for 1 month to different groups of mice that had previously received 3 months of chronic OVA challenge. A non-OVA challenged group served as a control. Lung sections from the different groups of mice were processed to detect the number of bFGF+ cells/bronchus. Chronic OVA challenge induced a significant increase in the number of $\mathrm{bFGF}+$ cells/bronchus $(\mathrm{p}<0.0001)$, which was significantly reduced by corticosteroid therapy ( $\mathrm{p}<0.0001)$ ( $\mathrm{n}=16$ mice/group).

cells/bronchus; $\mathrm{p}=0.0001$; fig. 7a). Corticosteroids significantly reduced the number of peribronchial FGF receptor-1+ cells in mice subjected to repetitive OVA challenge (corticosteroids + OVA vs. OVA: $10.1 \pm 1.5$ vs. 30.1 \pm 5.2 FGF receptor- $1+$ cells/bronchus; $p=0.03$; fig. $7 \mathrm{a}$ ).

\section{Chronic OVA Challenge Induces Expression of Both bFGF and TGF- $\beta 1$ by Macrophages in the Remodeled Airway}

Repetitive OVA challenge induced a significant increase in levels of bFGF (fig. 1b) as well as an associated significant increase in lung TGF- $\beta 1$ (OVA vs. no OVA: 

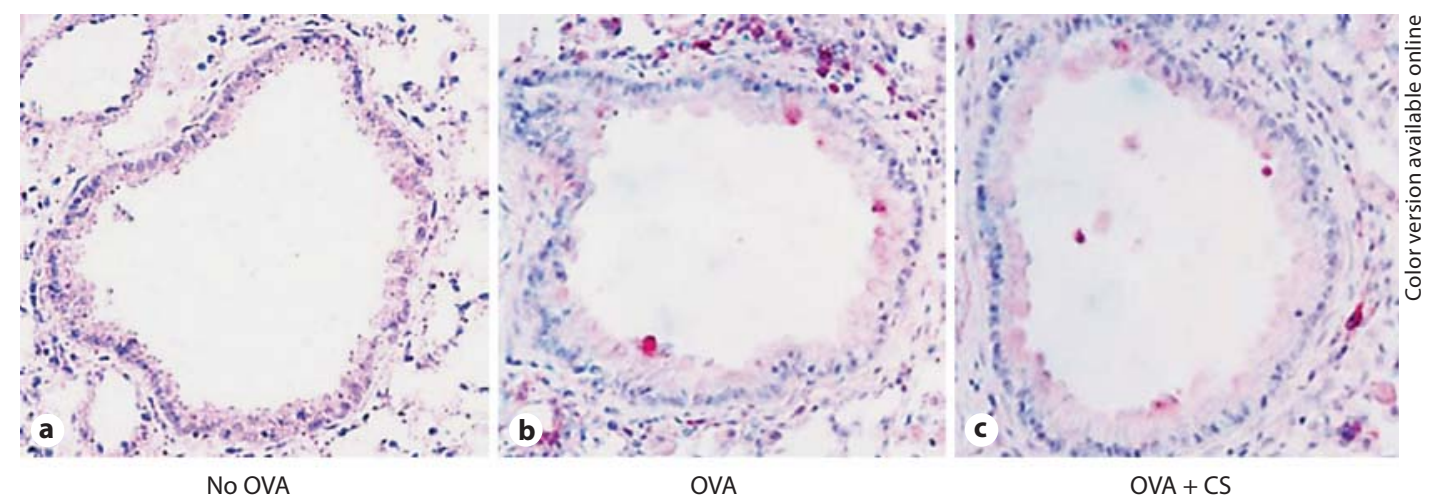

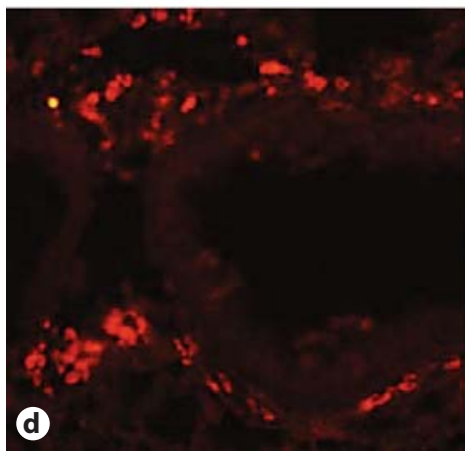

FGF receptor-1

Fig. 6. FGF receptor-1 is expressed by peribronchial mononuclear cells. Lung sections from mice that received no OVA (a), chronic OVA (b) or chronic OVA + corticosteroids (CS) (d) were processed for immunostaining with an anti-FGF receptor- $1 \mathrm{Ab}$. Mice chronically challenged with OVA had peribronchial cells expressing

$18.1 \pm 5.9$ vs. $7.0 \pm 1.5$ pg TGF- $\beta 1 / \mathrm{mg}$ lung protein; $\mathrm{p}=$ 0.0004; fig. 7b). Corticosteroids significantly reduced levels of lung bFGF (fig. 1b) and also lung TGF- $\beta 1$ (OVA vs. OVA + corticosteroid, $\mathrm{p}=0.04$; fig. $7 \mathrm{~b}$ ).

\section{bFGF and TGF- $\beta 1$ Are Coexpressed by Peribronchial}

Mononuclear Cells in the Remodeled Airway

We utilized double-label immunofluorescence microscopy to determine whether peribronchial macrophages coexpress bFGF and TGF- $\beta 1$. Figure $7 \mathrm{c}-\mathrm{e}$ demonstrates that the vast majority of bFGF+ peribronchial mononuclear cells in the remodeled airway are also TGF- $\beta 1+$.

\section{Assessment of Peripheral Blood Mononuclear Cell}

Expression of bFGF and TGF- $\beta 1$

Immunohistochemistry studies demonstrated that peripheral blood mononuclear cells did not express either bFGF (fig. 7f) or TGF- $\beta 1$ (fig. 7g) following OVA chal-

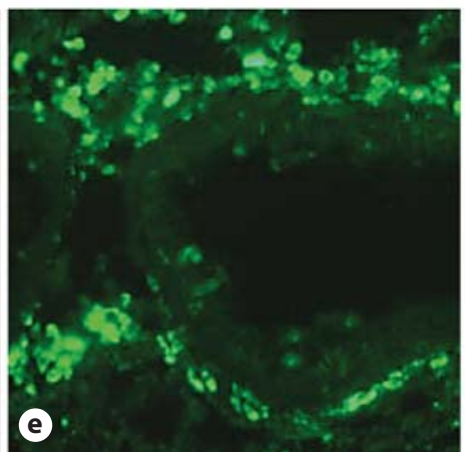

$\mathrm{F} 4 / 80$

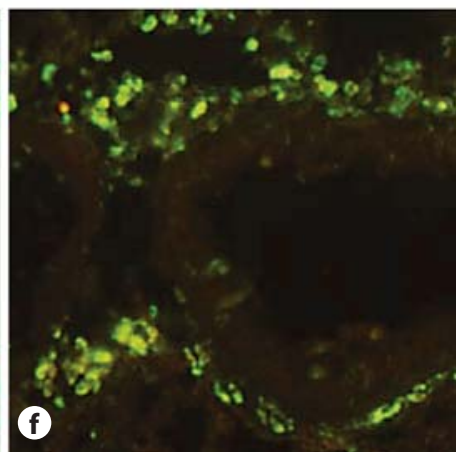

FGF receptor-1 and F4/80

FGF receptor-1 (red immunofluorescence; d) as well as F4/80 (green immunofluorescence; e). Peribronchial cells expressing both FGF receptor-1 and F4/80 demonstrated yellow immunofluorescence (f).

lenge. This contrasted with the large number of lung macrophages that expressed both bFGF (fig. 4a) and TGF- $\beta 1$ (fig. $7 \mathrm{~d}$ ) following OVA challenge.

\section{bFGF Induces Bone Marrow-Derived Macrophages to}

Express TGF- $\beta 1$ in vitro

As our immunohistochemistry studies demonstrated that bFGF receptors in the remodeled airway were predominantly expressed by F4/80+ mononuclear cells, we examined in vitro whether activation of bFGF receptors on bone marrow-derived macrophages would induce expression of pro-airway remodeling cytokines such as TGF- $\beta 1$. In these studies, incubation of purified populations of bone marrow-derived macrophages with varying concentrations of bFGF demonstrated that $100 \mathrm{ng} / \mathrm{ml}$ bFGF induced macrophages to release significant amounts of TGF- $\beta 1$ (bFGF vs. no bFGF: $73.2 \pm 7.6$ vs. $15.6 \pm 7.4 \mathrm{pg} / \mathrm{ml} ; \mathrm{p}=0.0001 ;$ fig. 8). 

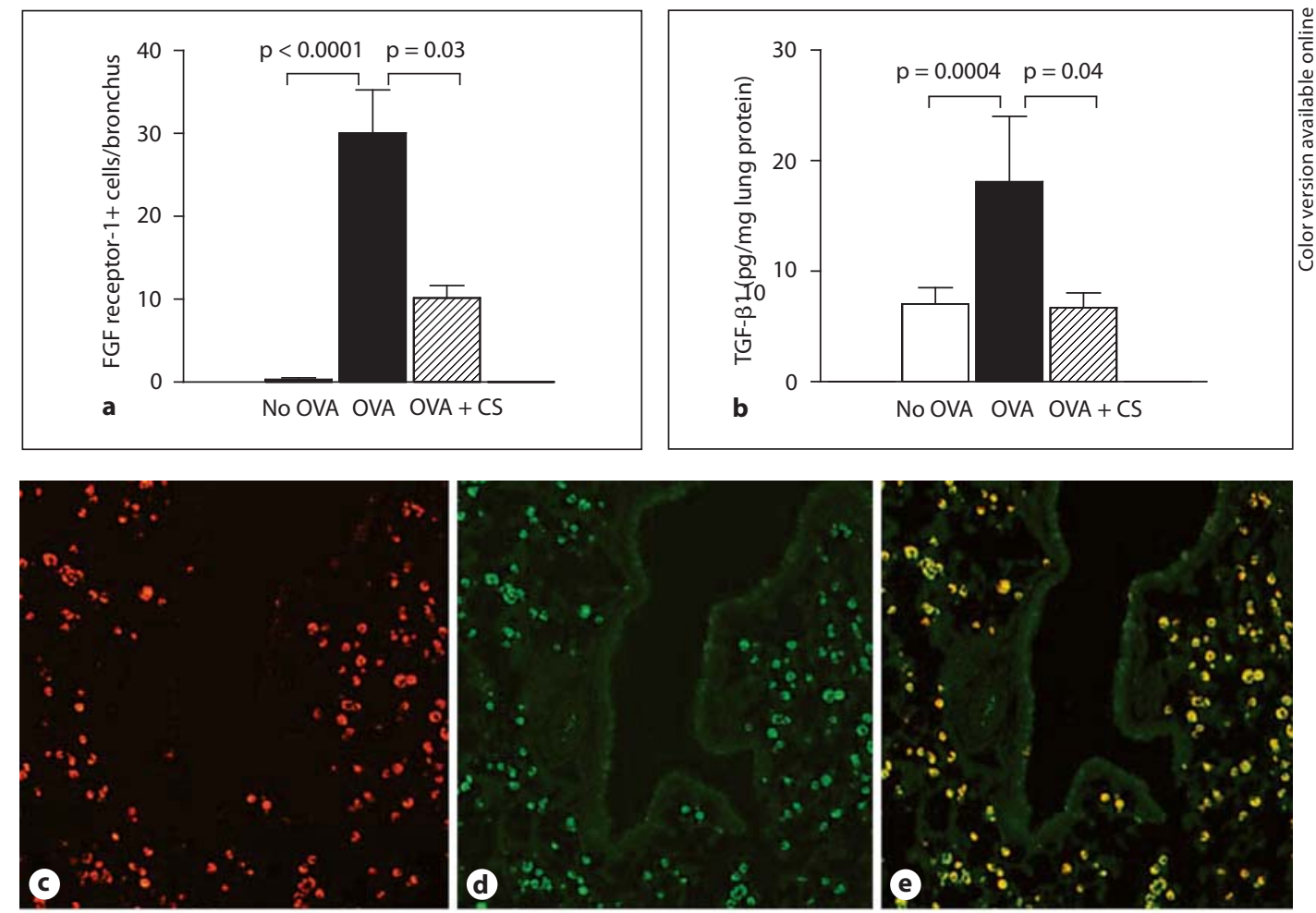

bFGF

TGF- $\beta 1$

bFGF and TGF- $\beta 1$

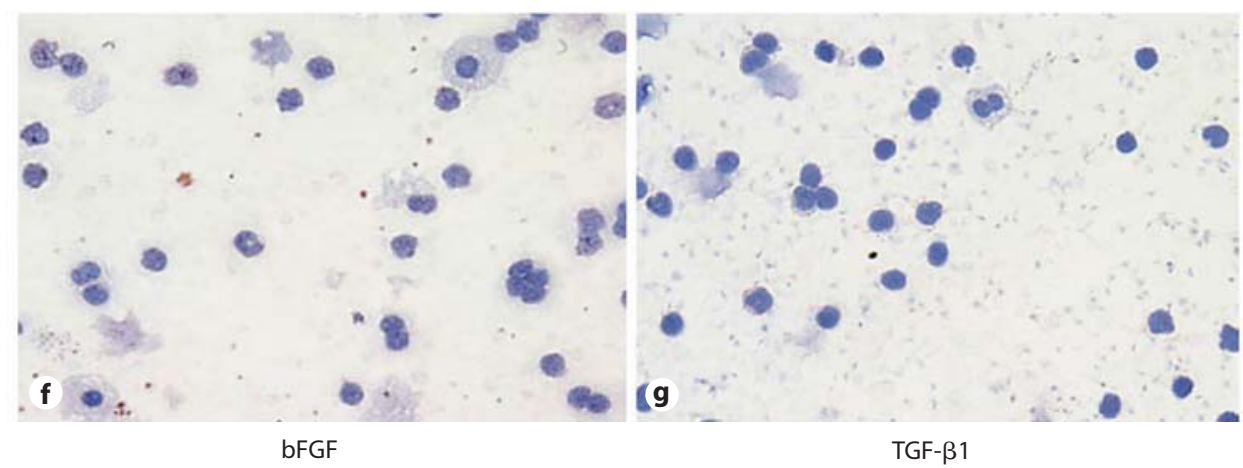

Fig. 7. Detection of peribronchial cells coexpressing bFGF and TGF- $\beta 1$. a Lungs from different groups of mice $(n=16$ mice/ group) were processed for immunohistochemistry with an antiFGF receptor-1 Ab. The number of FGF receptor-1+ cells/bronchus was quantitated by image analysis. b Levels of lung TGF- $\beta 1$ were quantitated by ELISA in specimens derived from different groups of mice ( $\mathrm{n}=16$ mice/group). Mice chronically challenged with OVA had peribronchial cells expressing bFGF (red immunofluorescence; c) as well as TGF- $\beta 1$ (green immunofluorescence; d). Peribronchial cells expressing both bFGF and TGF- $\beta 1$ demonstrated yellow immunofluorescence (e). Neither bFGF (f) nor TGF- $\beta 1$ (g) were detected by immunohistochemistry in peripheral blood mononuclear cells derived from OVA-challenged mice. $\mathrm{CS}=$ Corticosteroids

\section{Discussion}

Overall, this study demonstrates that allergen challenge upregulates coexpression of bFGF and TGF- $\beta 1$ by peribronchial macrophages and that bFGF may potentiate macrophage release of TGF- $\beta 1$ through autocrine and/or paracrine pathways. In addition, we have demonstrated that allergen challenge induces expression of bFGF and FGF receptor-1 in the remodeled airway and that corticosteroids reduce levels of both bFGF and FGF receptor-1 in the remodeled airway. We also made the novel observation that bFGF may influence levels of air- 


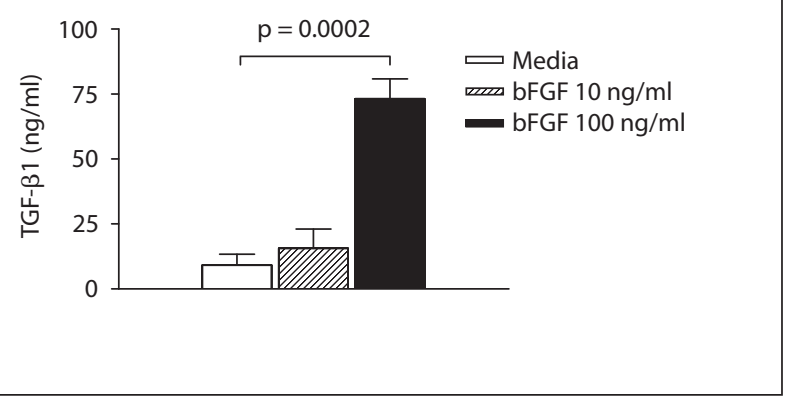

Fig. 8. bFGF induces macrophage expression of TGF- $\beta 1$ in vitro. Bone marrow-derived macrophages were incubated in vitro for $72 \mathrm{~h}$ with media or different concentrations of bFGF. TGF- $\beta 1 \mathrm{lev}-$ els in macrophage supernatants were quantitated by ELISA.

way remodeling not only through direct mitogenic effects on structural cells such as smooth muscle $[2,3]$ and fibroblasts [4], but also through indirect effects on cells such as macrophages, which are induced by bFGF to express the proremodeling cytokine TGF- $\beta 1$. Evidence to support the observation that bFGF induces macrophages to express TGF- $\beta 1$ includes in vitro studies with bone marrow-derived macrophages that express TGF- $\beta 1$ in response to incubation with bFGF. In addition, in vivo studies demonstrate that peribronchial $\mathrm{F} 4 / 80+$ macrophages express FGF receptor-1 and are thus able to respond to bFGF, which we demonstrated to be expressed in the remodeled airway by macrophages and airway epithelial cells. Thus, peribronchial macrophage FGF receptors may be activated by paracrine release of bFGF from airway epithelial cells, macrophages and other cells expressing bFGF in the remodeled airway, as well as potentially through autocrine release of bFGF by macrophages binding to FGF receptor-1 on the same cell. The ability of FGF receptor-1+ macrophages to respond to bFGF and release TGF- $\beta 1$ in vivo in the remodeled airway is suggested from double immunofluorescence studies demonstrating that individual peribronchial mononuclear cells coexpress bFGF and TGF- $\beta 1$. Thus, bFGF may exert proremodeling effects in the airway through direct effects on structural cells and/or indirectly through stimulation of TGF- $\beta 1$ expression by macrophages. Our studies demonstrating a lack of bFGF and TGF- $\beta 1$ expression in peripheral blood mononuclear cells suggest that the signal for induction of bFGF and TGF- $\beta 1$ expression likely arises in the lungs of OVA-challenged mice. Corticosteroids reduced levels of bFGF, FGF receptor-1 and TGF- $\beta 1$ in the remodeled airway. However, this study was unable to determine the relative contribution of bFGF-mediated TGF- $\beta 1$ expression to features of airway remodeling in vivo. Until studies are performed to inhibit bFGF in vivo, it is not possible to define the extent to which bFGF contributes to airway remodeling.

As murine models of allergen-induced airway remodeling may or may not reflect events in human disease, further validation of these results in studies of human asthmatic subjects with airway remodeling is needed. Thus far, the majority of human studies of bFGF in asthma have studied sputum [7] and BAL $[6,8]$ but have not used bronchial biopsies to determine whether bFGF is associated with features of airway remodeling such as smooth muscle changes and peribronchial fibrosis. One study of atopic asthmatics demonstrated that there is a significant correlation between bFGF+ cells and bronchial submucosal vascularity [23]. As bFGF is a known inducer of angiogenesis, bFGF may play a role in mediating angiogenesis in asthma, in addition to vascular endothelial growth factor and other angiogenic cytokines. To date, no human studies have explored which cells in the airway of asthmatics express FGF receptor-1 nor examined whether bFGF expression is found in areas of airway remodeling exhibiting smooth muscle changes and peribronchial fibrosis.

While our hypothesis that bFGF expression in the remodeled airway may contribute to increased levels of TGF- $\beta 1$ and increased levels of airway remodeling is supported by several studies suggesting an important role for TGF- $\beta 1$ and Smad $2 / 3$ in mediating airway remodeling $[18,19,24]$, there are also studies which demonstrate that an anti-TGF- $\beta 1 \mathrm{Ab}$ does not reduce remodeling in mice [25]. The differences in the results of these studies may be due to differences in the mouse models used in terms of the antigen dose, route of antigen delivery (intranasal vs. nebulized), duration of antigen administration (weeks vs. months) and type of antigen used (OVA vs. house dust mite extract) in the different studies $[18,19,24,25]$. In addition, there are studies that used an acute OVA asthma mouse model not associated with airway remodeling, demonstrating that exogenous administration of bFGF reduces airway responsiveness (assessed by enhanced pause), lung inflammation and mucus [26]. Thus, further studies in which bFGF is neutralized in models of chronic allergen challenge associated with remodeling are needed to determine the role of bFGF in airway remodeling.

Studies in cell types other than lung macrophages have also examined the interaction between bFGF and TGF$\beta 1$ in vitro. For example, in rat C6 glioma cells and astro- 
cytes, bFGF induced expression of TGF- $\beta 1$, which was mediated by MEK/ERK signaling and AP-1 activation [27]. In smooth muscle cells, bFGF antagonizes TGF- $\beta 1$ induced smooth muscle gene expression [28]. These in vitro studies suggest additional mechanisms by which bFGF and TGF- $\beta 1$ may interact, depending upon the responding cell type. While our in vitro studies demonstrate that bFGF can induce macrophages to express TGF- $\beta 1$ in vitro, the concentration of bFGF needed in vitro is higher than the levels of bFGF we detected in BAL fluid. However, the concentrations of bFGF detected in BAL may underestimate local lung macrophage concentrations of bFGF. This could be due to bFGF in BAL being diluted with the lavage fluid as well as the fact that BAL levels reflect a different compartment from the airway and may not accurately reflect higher levels of bFGF at the cell surface of macrophages in tissues. Interestingly, in vivo studies have demonstrated persistent subcutaneous fibrosis in newborn mice injected with both bFGF and TGF- $\beta 1$ [29], underscoring the potential importance of coexpression of $\mathrm{bFGF}$ and TGF- $\beta 1$ to airway remodeling.

In this study, we focused on the contribution of macrophage expression of bFGF and TGF- $\beta 1$ to airway remodeling. However, the macrophage is not the only cellular source of TGF- $\beta 1$ in mouse models of allergen-induced airway remodeling, as peribronchial eosinophils are also a significant source of TGF- $\beta 1$ [20]. Human studies of asthmatics have also demonstrated that both macrophages [30] and eosinophils [31,32] are important sources of TGF- $\beta 1$. In addition, structural cells such as epithelial cells can contribute to levels of TGF- $\beta 1$ in asth- ma [24]. Thus, while our study demonstrates that macrophages express TGF- $\beta 1$ in the remodeled airway, other cellular sources of TGF- $\beta 1$ can also contribute to airway remodeling.

In summary, in this study we have demonstrated that bFGF and FGF receptor-1 expression is upregulated in the remodeled airways of mice chronically challenged with allergen. bFGF expression is induced in peribronchial macrophages that express FGF receptor-1, suggesting that macrophages could be activated through autocrine release of bFGF and/or paracrine release of bFGF from airway epithelial cells or macrophages. In vitro studies demonstrated that bFGF induces macrophages to express the proremodeling cytokine TGF- $\beta 1$, while in vivo studies demonstrated that macrophages coexpress bFGF and TGF- $\beta 1$, supporting the notion that autocrine and/or paracrine production of bFGF may induce macrophage TGF- $\beta 1$ expression. Finally, we demonstrated that corticosteroids reduce levels of bFGF, FGF receptor-1 and TGF- $\beta 1$ in the remodeled airway. Further studies in which bFGF or FGF receptor-1 are neutralized in vivo in mice and humans are needed to determine their role in allergen-induced airway remodeling.

\section{Acknowledgements}

The current affiliation of H.Y.Y. is: Department of Pediatrics, Seoul Medical Center of Korea, Seoul, Korea.

This study was supported by NIH grants AI 38425, AI 70535 and AI 72115 (D.H.B.).

\section{References}

1 Broide DH: Immunologic and inflammatory mechanisms that drive asthma progression to remodeling. J Allergy Clin Immunol 2008; 121:560-570.

-2 Bosse Y, Rola-Pleszczynski M: FGF-2 in asthmatic airway-smooth-muscle-cell hyperplasia. Trends Mol Med 2008;14:3-11.

- 3 Bosse Y, Thompson C, Stankovz J, RolaPleszczynski M: Fibroblast growth factor 2 and transforming growth factor $\beta 1$ synergism in human bronchial smooth muscle cell proliferation. Am J Respir Cell Mol Biol 2006;34:746-753.

4 Strutz F, Seisberg M, Renziehausen A, Raschke B, Becker V, van Kooten C, Muller GA: TGF- $\beta 1$ induced proliferation in human renal fibroblasts via induction of basic fibroblast growth factor (FGF-2). Kidney Int 2001; 59:579-892.
5 Friesel RE, Maciag T: Molecular mechanisms of angiogenesis: fibroblast growth factor signal transduction. FASEB J 1995;9:919925.

-6 Shute JK, Solic N, Shimizu J, McConnel W, Redington AE, Howarth PH: Epithelial expression and release of FGF-2 from heparin sulphate binding sites in bronchial tissue in asthma. Thorax 2004;59:557-562.

7 Kanazawa H, Yoshikawa J: Up-regulation of thrombin activity induced by vascular endothelial growth factor in asthmatic airways. Chest 2007;132:1169-1174.

$\checkmark 8$ Redington AE, Roche WR, Madden J, Frew AJ, Djukanovic R, Holgate ST, Howarth PH: Basic fibroblast growth factor in asthma: measurement in bronchoalveolar lavage fluid basally and following allergen challenge. J Allergy Clin Immunol 2001;107:384-387.
9 Itoh N, Ornitz DM: Evolution of the FGF and FGFR gene families. Trends Genet 2004;20: 563-569.

10 Itoh N, Ornitz DM: Functional evolutionary history of the mouse FGF gene family. Dev Dyn 2008;237:18-27.

11 Klint P, Claesson-Welsh L: Signal transduction by fibroblast growth factor receptors. Front Biosci 1999;4:D165-D177.

12 Kwabi-Addo B, Ozen M, Ittmann M: The role of fibroblast grow th factors and their receptors in prostate cancer. Endocr Relat Cancer 2004;11:709-724.

$\checkmark 13$ Powers CJ, McLeskey SW, Wellstein A: Fibroblast growth factors, their receptors and signaling. Endocr Relat Cancer 2000;7:165197. 
-14 Cordon-Cardo C, Vlodavsky I, HaimovitzFriedman A, Hicklin D, Fuks Z: Expression of basic fibroblast growth factor in normal human tissues. Lab Invest 1990;63:832-840.

- 15 Qu Z, Kayton RJ, Ahmadi P, Liebler JM, Powers MR, Planck SR, Rosenbaum JT: Ultrastuctural immunolocalization of basic fibroblast growth factor in mast cell secretory granules: morphological evidence for bFGF release through degranulation. J Histochem Cytochem 1998;46:1119-1128.

-16 Mignatti P, Morimoto T, Rifkin DB: Basic fibroblast growth factor, a protein devoid of secretory signal sequence, is release by cells via a pathway independent of the endoplasmic reticulum-Golgi complex. J Cell Physiol 1992;151:81-93.

-17 Mignatti P, Morimoto T, Rifkin DB: Basic fibroblast growth factor released by single, isolated cells stimulates their migration in an autocrine manner. Proc Natl Acad Sci USA 1991;88:11007-11011.

-18 Le AV, Cho JY, Miller M, McElwain S, Golgotiu $\mathrm{K}$, Broide $\mathrm{DH}$ : Inhibition of allergeninduced airway remodeling in Smad 3-deficient mice. J Immunol 2007;178:7310-7316.

19 McMillan SJ, Xanthou G, Lloyd CM: Manipulation of allergen-induced airway remodeling by treatment with anti-TGF-beta antibody: effect on the Smad signaling pathway. J Immunol 2005;17:5774-5780.

-20 Cho JY, Miller M, Baek KJ, Han JW, Nayar J, Lee SY, McElwain K, McElwain S, Friedman $\mathrm{S}$, Broide $\mathrm{DH}$ : Inhibition of airway remodeling in IL-5-deficient mice. J Clin Invest 2004; 113:551-560.
21 Cho JY, Miller M, Baek KJ, Han JW, Nayay J, Lee SY, McElwain K, McElwain S, Raz E, Broide DH: Immunostimulatory DNA reverses established allergen-induced airway remodeling. J Immunol 2004; 173:75567564.

22 Cho JY, Miller M, McElwain S, Broide DH: Combination of corticosteroid therapy and allergen avoidance reverses allergen-induced airway remodeling in mice. J Allergy Clin Immunol 2005;116:1116-1122.

23 Hoshino M, Takahashi M, Aoike N: Expression of vascular endothelial growth factor, basic fibroblast growth factor, and angiogenin immunoreactivity in asthmatic airways and its relationship to angiogenesis. J Allergy Clin Immunol 2001;107:295-301.

24 Alcorn J, Rinaldi L, Jaffe E, van Loon M Bates J, Janssen-Heininger Y, Irvin C: Transforming growth factor- $\beta 1$ suppresses airway hyperresponsiveness in allergic airway disease. Am J Respir Crit Care Med 2007;176: 974-982.

25 Fattouh R, Midence G, Arias K, Johnson H, Walker T, Concharova S, Souza K, Gregory R, Lonning S, Gauldie J, Jordana M: Transforming growth factor- $\beta$ regulates house dust mite-induced allergic airway inflammation but not airway remodeling. Am J Respir Crit Care Med 2008;177:593-603.

26 Jeon SG, Lee CG, Oh MH, Chun EY, Gho YS, Cho SH, Kim JH, Min KU, Kim YY, Kim YK, Elias JA: Recombinant basic fibroblast growth factor inhibits the airway hyperresponsiveness, mucus production, and lung inflammation induced by an allergen challenge. J Allergy Clin Immunol 2007;119:831837.

-27 Dhandapani KM, Khan MM, Wade FM, Wakade C, Mahesh VB, Brann DW: Induction of transforming growth factor- $\beta 1$ by basic fibroblast growth factor in rat $\mathrm{C} 6$ glioma cells and astrocytes is mediated by MEK/ ERK signaling and AP-1 activation. J Neurosci Res 2007;85:1033-1045.
28 Kawai-Kowase K, Sato H, Oyama Y, Kanai H, Sate M, Doi H, Kurabayashi M: Basic fibroblast growth factor antagonizes transforming growth factor- $\beta 1$-induced smooth muscle gene expression through extracellular signal-regulated kinase $1 / 2$ signaling pathway activation. Arterioscler Thromb Vasc Biol 2004;24:1384-1390.

29 Shinozaki M, Kawara S, Hayashi N, Kakinuma T, Igarashi A, Takehara K: Induction of subcutaneous tissue fibrosis in newborn mice by transforming growth factor beta simultaneous application with basic fibroblast growth factor causes persistent fibrosis. Biochem Biophys Res Commun 1997;237: 292-296.

-30 Vignola AM, Chanez P, Chiappara G, Merendino $\mathrm{A}$, Zinnati $\mathrm{E}$, Bousquet J, Bellia V, Bonsignore G: Release of transforming growth factor-beta (TGF- $\beta$ ) and fibronectin by alveolar macrophages in airway diseases. Clin Exp Immunol 1996;106:114-119.

-31 Flood-Page P, Menzies-Gow A, Phipps S, Ying S, Wangoo A, Ludwig MS, Barnes N, Robinson D, Kay AB: Anti-IL-5 treatment reduces deposition of ECM proteins in the bronchial subepithelial basement membrane of mild atopic asthmatics. J Clin Invest 2003; 112:1029-1036.

-32 Balzar S, Chu HW, Silkoff P, Cundall M, Trudeau JB, Strand M, Wenzel S: Increased TGF- $\beta 2$ in severe asthma with eosinophilia. J Allergy Clin Immunol 2005;115:110-117. 